\begin{tabular}{|c|c|c|}
\hline 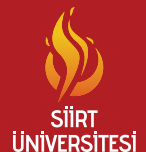 & $\begin{array}{c}\text { Türkiye Tarımsal Araştırmalar Dergisi } \\
\text { dergipark.org.tr/tutad }\end{array}$ & $\begin{array}{l}\text { Turk J Agric Res } \\
\text { 2020, 7(2): 128-135 } \\
\text { @ TÜTAD } \\
\text { ISSN: 2148-2306 } \\
\text { e-ISSN: 2528-858X }\end{array}$ \\
\hline Bdimin Psugunda & Araştırma Makalesi / Research Article & doi: $10.19159 /$ tutad.655120 \\
\hline
\end{tabular}

\title{
Bazı Örtücü Bitkilerin Trabzon Hurması (Diospyros kaki L.)’nda Verim ve Meyve Kalitesine Etkilerinin Araştırılması
}

\author{
İdris MACiT ${ }^{1}$, Kübra KALE ${ }^{2}$, Zeynep DEMİ ${ }^{3}$, Mahmut DOK ${ }^{4}$, Kibar AK ${ }^{5}$, Doğan IȘIK ${ }^{2 *}$ \\ ${ }^{1}$ Karadeniz Tarımsal Araştırma Enstitüsü Müdürlüğü, Bahçe Bitkileri Bölümü, Samsun, TÜRKIYYE \\ ${ }^{2}$ Erciyes Üniversitesi, Seyrani Ziraat Fakültesi, Bitki Koruma Bölümü, Kayseri, TÜRKIYYE \\ ${ }^{3}$ Toprak, Gübre ve Su Kaynakları Merkez Araştırma Enstitüsü Müdürlüğü, Toprak ve Bitki Besleme Bölümü, Ankara, TÜRKIYE \\ ${ }^{4}$ Karadeniz Tarımsal Araştırma Enstitüsü Müdürlü̆̆̈̈, Enerji Tarımı Bölümü, Samsun, TÜRKIYYE \\ ${ }^{5}$ Karadeniz Tarımsal Araştırma Enstitüsü Müdürlü̆̆̈̈, Bitki Sağlı̆̆ı Bölümü, Samsun, TÜRKIYYE
}

\begin{tabular}{|c|c|}
\hline Geliş Tarihi/Received: 05.12 .2019 & Kabul Tarihi/Accepted: 05.06 .2020 \\
\hline \multicolumn{2}{|l|}{ ORCID ID (Yazar surasina göre / by author order) } \\
\hline \multicolumn{2}{|c|}{ (1D) orcid.org/0000-0001-6506-0758 (Dorcid.org/0000-0003-4137-8782 (Dorcid.org/0000-0002-7589-3216 } \\
\hline (1) orcid.org/0000-0002-1558-7452 (1) orcid.org/0000-0002-800 & d.org/0000-0002-0554-2912 \\
\hline
\end{tabular}

Öz: Bu çalıșma; Trabzon hurması (Diospyros kaki L.) bahçelerinde yabancı otlarla mücadelede kullanılan bazı örtücü bitkilerin, verim ve kalite üzerine etkilerinin araştırılması amacıyla 2013-2014 yıllarında, Samsun'da yürütülmüştür. Calıșma, tesadüf blokları deneme desenine göre dört tekerrürlü olarak kurulmuștur. Araștırmada Trifolium repens, Festuca rubra rubra, Festuca arundinacea ve bu türlerin sırasıyla \% 40+30+30 oranındaki karışımı, Vicia villosa ve Trifolium meneghinianum'dan oluşan örtücü bitki parselleri ile mekanik mücadele, herbisitle mücadele parselleri ve yabanc1 otlu kontrol parseli olmak üzere 9 farklı uygulama ele alınmıştır. Araştırma sonucunda, uygulamaların Trabzon hurması verimini etkiledikleri tespit edilmiştir. Çalışmada; en yüksek dekara verim $1617.5 \mathrm{~kg} \mathrm{da}^{-1}$ ile $V$. villosa parsellerinden elde edilirken, en düşük dekara verim ise $355.7 \mathrm{~kg} \mathrm{da}^{-1}$ ile yabancı otlu kontrol parsellerinden elde edilmiştir. Meyve boyu değerleri en yüksek $69.0 \mathrm{~mm}$ ile herbisitle mücadele parsellerinde, en düşük $45.2 \mathrm{~mm}$ ile $F$. rubra rubra parsellerinde olmuştur. Meyve eni değerlerinde istatistiki açıdan iki grup oluşmuş, $74.7 \mathrm{~mm}$ ile $F$. arundinaceae, $71.5 \mathrm{~mm}$ ile $F$. rubra rubra, 71.3 ile herbisitle mücadele parselleri yüksek grupta yer almıştır. Şekil indeksinde ise en yüksek oran 1.15 ile $T$. meneghinianum parsellerinde, en düşük 0.80 ile $F$. arundinacea parsellerinden elde edilmiștir. Meyve ağırlığı değerleri en yüksek $165.5 \mathrm{~g}$ ile $F$. arundinacea parsellerinde, en düşük ise $109.9 \mathrm{~g}$ ile $T$. repens, F. rubra rubra, F. arundinacea karışımı parsellerinde bulunmuştur. Suda çözünebilir kuru madde oranları ise en yüksek \% 21.2 ile T. repens, F. rubra rubra, F. arundinacea karışımı parsellerinden, en düşük \% 18.3 ile $V$. villosa parsellerinden elde edilmiştir. Çalışma sonucuna göre örtücü bitkilerin Trabzon hurması bahçelerinde verim ve kalite üzerine olumlu etki yaptıkları için yabancı otlarla mücadelede alternatif olarak önerilebilecekleri belirlenmiştir.

Anahtar Kelimeler: Trabzon hurmas1, canlı malç, Vicia villosa, Trifolium repens, Festuca rubra rubra, Festuca arundinacea

\section{The Effects of Some Cover Crops on Yield and Fruit Quality in Persimmon (Diospyros kaki L.)}

\footnotetext{
Abstract: This study was carried out in Samsun province between 2013 and 2014 to investigate the effects of some cover crops, used for weed control in the persimmon orchards, on yield and quality of the fruits. The study was conducted according to the randomized complete blocks design with four replications. The research was carried out with 9 different applications; cover crop plots with Trifolium repens, Festuca rubra rubra, Festuca arundinacea and a $40+30+30$ percent mixture of these species, Vicia villosa, Trifolium meneghinianum, mechanical control plots, herbicides control plots and weedy control plots. As a result of the research, it was determined that the applications affected the persimmon yield. The highest yield per decare was obtained from $V$. villosa plots with $1617.5 \mathrm{~kg} \mathrm{da}^{-1}$, while the lowest yield per decare was
} 
obtained from weed control plots with $355.7 \mathrm{~kg} \mathrm{da}^{-1}$. The highest fruit size of $69.0 \mathrm{~mm}$ was obtained from herbicide control plots, whereas the lowest fruit size was obtained from $F$. rubra rubra plots with $45.2 \mathrm{~mm}$. Two groups were obtained for fruit width. F. arundinacea, F. rubra rubra, and herbicide control plots were in the higher group with $74.7 \mathrm{~mm}, 71.5 \mathrm{~mm}$, and $71.3 \mathrm{~mm}$ of fruit width respectively. As for the shape index, the highest rate of 1.15 was observed at the $T$. meneghinianum plots and the lowest rate of 0.80 was observed at the $F$. arundinacea plots. The highest fruit weight of 165.5 $\mathrm{g}$ was obtained from the $F$. arundinacea plots and the lowest fruit weight of $109.9 \mathrm{~g}$ was from the plots with the mixture of T. repens, F. rubra rubra, F. arundinacea. Water-soluble dry matter (WSDM) rates were found to be the highest for the plots with the mixture of T. repens, F. rubra rubra, F. arundinacea with a value of $21.2 \%$, whereas the lowest WSDM rates were obtained from $V$. villosa plots with a value of $18.3 \%$. According to the results of the study, it has been determined that the cover crops can be recommended as an alternative in weed control agents since they do affect the yield and quality in persimmon orchards.

Keywords: Persimmon, live mulch, Vicia villosa, Trifolium repens, Festuca rubra rubra, Festuca arundinacea

\section{Giris}

Türkiye 20 milyon ton civarında yıllık meyve üretimiyle (Anonim, 2019), hem yurt içi gereksinimini karşılamakta hem de yurt dışına ihracat yapmaktadır. Türkiye ekonomisine önemli katkısı olan bahçe bitkileri, ülke tarımında önemli bir konuma sahiptir. Fındık, elma, kiraz, kayısı gibi bazı meyve türlerinde ihracatçı durumda olan Türkiye, bazı türlerde de hızlı üretim artışına sahiptir (Tursun ve ark., 2018). Bunlardan biri olan Trabzon hurması (Diospyros kaki L.) A vitamini ve karbonhidratlar başta olmak üzere birçok besin maddesi bakımından zengin bir meyvedir (Özcan, 2005). Trabzon hurmasinın taze ve kurutularak tüketiminin yanı sira pekmez, püre, meyve suyu gibi gıda sanayi alanlarında da kullanımı giderek yaygınlaşmaktadır. $\mathrm{Bu}$ özelliklerinden dolayı gelişmekte olan Trabzon hurmasının Türkiye'deki üretimi; Türkiye İstatistik Kurumu verilerine göre 2000 yılında 12000 ton iken, 2018 yilında 46676 tona yükselmiştir (Anonim, 2019).

Trabzon hurmasında üretimi kısıtlayan birçok biyotik ve abiyotik etken bulunmaktadır. Yabancı otlar, Trabzon hurmasinda üretimi etki eden en önemli faktörlerden birisidir. Türkiye'de Trabzon hurması bahçelerinde yabancı otlarla mücadele, total herbisitler ve mekanik mücadeleye bağlı olarak yürütülmektedir. Herbisitlerin oluşturduğu değişik yan etkiler, mekanik mücadelede bitkiye zarar verilmesi, işçilik maliyetlerinin yüksek olması ve toprak yüzeyindeki organik madde miktarını etkilemesinden dolayı alternatif mücadele metotlarına ihtiyaç duyulmaktadır. Trabzon hurması bahçelerinde yabancı otlarla mücadelede örtücü bitkilerin kullanılması bu alternatiflerin başında gelmektedir.

Son yıllarda Karadeniz Bölgesi'nde de findığın yanı sıra kapama Trabzon hurması bahçeleri oluşturulmaya başlanmıştır. Talebin giderek artması ve Trabzon hurmasinın hizla yaygınlaşması, bölgenin önemli gelir kaynakları arasında yerini alma eğiliminde olduğunu göstermektedir.
Meyvecilikte yabancı otlarla mücadelede total herbisitlerin yanında mekanik mücadele amaçlı toprak işleme yaygın olarak kullanılmaktadır. Meyve ağaçlarında kökler taç izdüşümüne kadar gelişmektedir. Toprak işleme özellikle toprak yüzeyine yakın ve ağacın beslenmesini sağlayan kılcal köklerin kesilmesine neden olmaktadır. Bu durum meyve ağaçlarının besin alımını engellemekte ve açılan yaralardan hastalık etmenlerinin bulaşması söz konusu olmaktadır. Bundan dolayı, gerekmedikçe toprak işlemenin yapılmamas1 modern tarım sistemlerinde tavsiye edilmektedir. Dünyanın bazı gelişmiş ülkelerinde olduğu gibi Türkiye'deki meyve bahçelerinde de toprak işleme yerine, hem agroekosistemin dengesini bozmadan yabancı ot kontrolü yapacak hem de biyoçeşitliliği arttırıcı önlemler alarak meyve bahçelerinde zararlı diğer etmenlerin doğal dengeyi koruyarak kontrolünü sağlayacak uygulamaların yaygınlaştırılması sağlanmalıdır. Örtücü bitki uygulamaları bu yöntemlerden birisidir (Kitiş, 2010; Tursun ve ark., 2018).

Son yıllarda bilhassa Avrupa'daki meyve bahçelerinde sıkça göze çarpan örtücü bitki uygulamalarının mekanik blokaj, allelopati ve doğal rekabet yoluyla yabancı otların gelişimini baskıladığ 1 (Isık ve ark., 2009, Isik ve ark., 2014); toprak yapısını iyileştirip su içeriğini düzenlediği, toprağın karbon dinamiklerini, organik madde miktarını ve mikrobiyal fonksiyonlarını arttırarak toprak kalitesini iyileștirip, toprak verimliliğine önemli katkılar sağladığı (Robacer ve ark., 2016; Demir ve ark., 2019; Demir ve Isik, 2019); toprak erozyonunu önlediği (Isık ve ark., 2009, Isik ve ark., 2014); baklagil olan türlerin toprağa azot fikse ettiği, birçok faydalı böcek için insektaryum vazifesi gördüğü, toprak solucanlarında olduğu gibi makrofaunayı zenginleştirdiği (Demir ve ark., 2019; Demir ve Isik, 2019) bildirilmektedir. Öte yandan, Türkiye'de özellikle yağışı bol olan Karadeniz Bölgesi'nde herbisit uygulaması ile toprak yüzeyi boş kalmakta ve toprak yüzeyinden yağış ve rüzgârla erozyon meydana gelmektedir. Bununla birlikte örtücü bitkiler, örtücü bitki türüne 
ve bölgenin iklim şartlarına bağlı olarak meyve verimi ve kalitesini de etkilemektedirler (Alvarez ve ark., 2017, Işık ve ark., 2018). Hoagland ve ark. (2008), yeni dikilmiş elma bahçelerinde canlı malç olarak Trifolium subterraneum, Medicago lupulina ve $M$. Polymorpha gibi örtücü bitkilerin kullanımının toprakta daha yüksek nitrat konsantrasyonu sağlayıp toprağın biyolojik aktivitesini geliştirdiğini, bununla birlikte rekabetten dolayı ağaç büyümesinde almalara neden olduğunu ifade etmişlerdir. Diğer taraftan Mullinix ve Granatstein (2011), Washington'da olgun bir elma bahçesine örtücü bitki olarak $T$. repens ekilmesinin ağaç büyümesini ve meyve verimini artırdığını, mükemmel yabancı ot kontrolü sağladığını ifade etmiștir. Türkiye'de son yıllarda kapama bahçeleri ile artmaya başlayan Trabzon hurması üretim alanlarında; zemin yönetiminde örtücü bitkilerin ilk kez kullanıldığ 1 bu çalışmada, örtücü bitkilerin ve diğer yabancı ot mücadele yöntemlerinin Trabzon hurmasında meyve verim ve kalitesine etkileri incelenmiştir.

\section{Materyal ve Yöntem}

Bu araştırma, Türkiye'de Karadeniz Bölgesi'nin orta bölümünde yer alan Samsun ili sınırları içerisindeki, Karadeniz Tarımsal Araştırma Enstitüsü Müdürlüğü'ne ait araştırma alanında (Enlem, 4113' Kuzey; boylam, 36³0' Doğu; yükseklik, $20 \quad \mathrm{~m}) \quad 2013-2014$ y1llarında yürütülmüştür. Araştırmanın yürütüldüğü Trabzon hurması bahçesi 12 yaşında olup, Diospyros lotus anacı üzerine aşı Yeşilırmak çeşidinden oluşmaktadır. Çalışmada, örtücü bitki olarak; Trifolium repens L. (Ak üçgül), Festuca rubra rubra L. (kırmızı yumak), Festuca arundinacea (Kamışsı yumak) ve $T$. repens $(\% 40), F$. rubra rubra (\% 30), F. arundinacea (\% 30) karışımı ile Vicia villosa Roth. (Tüylü fiğ) ile Trifolium meneghinianum Celm. (Gelemen üçgülü) kullanılmıștır.

Araştırmanın yürütüldüğü alana ait toprağın, bazı fiziksel ve kimyasal özellikleri Tablo 1'de verilmiștir. Araştırma toprakları; tuzsuz, killi-tınlı tekstürlü, nötr reaksiyonlu ve çok az düzeyde organik maddeye sahiptir (Tablo 1). Araştırma alanı 1lıman bir iklime sahip olup, çalışmanın yapıldı ğ1 yıllar ve uzun yıllar (1929-2018) ortalamasına ait veriler Tablo 2'de verilmiştir. Buna göre uzun yıllar ortalaması yıllık yağış miktarı $717.1 \mathrm{~mm}$, yıllık ortalama nispi nem $\% 70.6$ ve yillık ortalama sicaklık $14.5{ }^{\circ} \mathrm{C}$ 'dir (Tablo 2).

Araştırmada, denemeler tesadüf blokları deneme desenine göre dört tekerrürlü ve 9 konulu olarak kurulmuştur. Denemelerde, her parsel iki
Tablo 1. Araștırma yeri toprağının bazı fiziksel ve kimyasal özellikleri*

\begin{tabular}{lc}
\hline Toprak özelliği & Değeri \\
\hline Suyla duygunluk, \% & 57 \\
Toplam tuz, \% & 0.11 \\
$\mathrm{pH}$ & 7.46 \\
$\mathrm{Kireç}\left(\mathrm{CaCO}_{3}\right), \%$ & 0.68 \\
Organik madde, \% & 0.94 \\
Alınabilir fosfor, $\mathrm{kg} \mathrm{P}_{2} \mathrm{O}_{5} \mathrm{da}^{-1}$ & 13 \\
Alınabilir potasyum, kg K2 $\mathrm{O} \mathrm{da}^{-1}$ & 47 \\
\hline *: Analizler, Karadeniz Tarımsal Araştırma Enstitüsü & Müdürlüğü, \\
Toprak, Bitki ve Su Analiz Laboratuvarı'nda yapılmıștır.
\end{tabular}

adet Trabzon hurması ağacından oluşmakta olup, parsel büyüklükleri 5 x $7 \mathrm{~m}$ olacak şekilde planlanmıştır. Buna göre araştırmada deneme konularını; $T$. repens, $F$. rubra rubra, $F$. arundinacea bitkilerinin yalın haldeki ekimi, bu 3 bitkinin sirasıyla $\% 40, \% 30$ ve $\% 30$ oranındaki karışık ekimleri, $V$. villosa ve $T$. meneghinianum ekili parseller ile yabancı otlu kontrol parseli, mekanik mücadele parseli ve herbisitle mücadele yapılmış parseller oluşturmaktadır. Mekanik yabanc1 ot kontrolü diskaro ile yapılmıştır. Herbisitle mücadele parsellerinde ise glisofat izopropilamin tuzu (360 g a.i L $\left.\mathrm{L}^{-1}\right), 600 \mathrm{ml} \mathrm{da}$ dozunda uygulanmıştır. Glifosat, sırt pülverizatörü (Honda WJR 2225) ile $3 \mathrm{~atm}$ basınçta (303.97 kPa) ve $25 \mathrm{~L} \mathrm{da}^{-1}$ ilaç normunda uygulanmıştır. Herbisit uygulaması ve mekanik yabancı ot kontrolü geniş yapraklı yabancı otların 4-8 yapraklı, dar yapraklı yabanc1 otların ise $10-15 \mathrm{~cm}$ boyunda oldukları dönemde yapılmıştır.

Araştırmada, denemenin ilk kurulduğu 2013 yılında örtücü bitkiler Nisan başında ekilmiştir. $T$. repens, $5 \mathrm{~kg} \mathrm{da}^{-1}$ (Kır ve ark., 2009); F. rubra rubra ve $F$. arundinacea, $8 \mathrm{~kg} \mathrm{da}^{-1}$ (Elçi, 2005); $V$. villosa, $15 \mathrm{~kg} \mathrm{da}^{-1}$ (Çakmakçı ve Aydınoğlu, 2009); T. meneghinianum ise $5 \mathrm{~kg} \mathrm{da}^{-1}$ (Acar ve Ayan, 2009) ekim normunda ekilmiştir. Çalışmada, örtücü bitkilerin gelişmeleri periyodik olarak takip edilmiştir. Örtücü bitkilerin Trabzon hurmasının verimine etkisini araştırmak amacıyla, hasat olgunluğu döneminde parsel içerisinde yer alan ağaçlar hasat edilerek verim değerleri alınmıştır. Çalışmada meyve eni ve meyve boyu, meyve şekil indeksi, meyve ağırlığı ve suda çözünebilir kuru madde miktarı (SÇKM) gibi pomolojik gözlemler alınmıştır. Pomolojik gözlemler Onur ve Onur (1997)'a göre yapılmış olup, pomolojik analizler için her tekerrürden alınan 10'ar adet meyve kullanılmıştır.

Çalışma sonucunda elde edilen verilere homojenlik testinden sonra yıllar bazında ve yıl birleştirmesi şeklinde ayrı ayrı tek yönlü (ANOVA) varyans analizi uygulanmıştır. Uygulamalar arasındaki farklılıklar ise, Asgari Önemli Fark (Least Significant Difference, LSD; 
Tablo 2. Araştırma alanına ait 2013 ve 2014 yılları ve uzun yıllar bazı iklim verileri (Anonim, 2020)

\begin{tabular}{|c|c|c|c|c|c|c|c|c|c|}
\hline \multirow{2}{*}{ Aylar } & \multicolumn{3}{|c|}{ Ortalama sicaklık $\left({ }^{\circ} \mathrm{C}\right)$} & \multicolumn{3}{|c|}{ Nispi nem (\%) } & \multicolumn{3}{|c|}{ Toplam yağıș (mm) } \\
\hline & 2013 & 2014 & $1929-2018$ & 2013 & 2014 & 1929-2018 & 2013 & 2014 & 1929-2018 \\
\hline Ocak & 8.3 & 8.2 & 7.0 & 68.5 & 76.1 & 63.7 & 78.9 & 6.8 & 71.6 \\
\hline Şubat & 9.6 & 8.2 & 7.0 & 77.7 & 79.4 & 67.2 & 30 & 31.2 & 58.7 \\
\hline Mart & 10.4 & 9.9 & 7.9 & 72.8 & 77.8 & 71.9 & 63.8 & 49.9 & 66.4 \\
\hline Nisan & 13.1 & 12.2 & 11.2 & 79.1 & 80.6 & 76.7 & 77.7 & 22.7 & 57.0 \\
\hline Mayıs & 19.2 & 17.2 & 15.6 & 77.7 & 77.9 & 77.8 & 23.6 & 56.5 & 48.3 \\
\hline Haziran & 21.7 & 21.5 & 20.3 & 73.7 & 76.5 & 73.1 & 37.6 & 155.1 & 45.2 \\
\hline Temmuz & 23.5 & 24.4 & 23.3 & 72.2 & 75.1 & 70.8 & 58.6 & 10.1 & 34.4 \\
\hline Ağustos & 24.2 & 25.2 & 23.6 & 74 & 79.1 & 70.3 & 28.9 & 38.8 & 37.3 \\
\hline Eylül & 19.2 & 20.8 & 20.1 & 75.8 & 82.8 & 72.0 & 71.9 & 29.5 & 54.0 \\
\hline Ekim & 13.6 & 16.3 & 16.2 & 77 & 84.1 & 73.2 & 72.4 & 1.0 & 78.7 \\
\hline Kasım & 12.6 & 10.6 & 12.5 & 77.7 & 81.9 & 67.2 & 28.9 & 134.2 & 83.5 \\
\hline Aralık & 4.9 & 10.1 & 9.3 & 67.5 & 78.5 & 63.4 & 44.8 & 102.4 & 82.0 \\
\hline Ortalama & 15.02 & 15.38 & 14.5 & 74.47 & 79.15 & 70.6 & & & \\
\hline Toplam & & & & & & & 617.1 & 638.2 & 717.1 \\
\hline
\end{tabular}

p<0.05) çoklu karşılaştırma testine göre değerlendirilmiştir.

\section{Bulgular}

\section{1. Örtücü bitkilerin Trabzon hurmasında meyve boyuna etkisi}

Örtücü bitkilerin Trabzon hurmasında meyve boyuna etkisi, yapılan varyans analizine göre y1l bazında ve yıl birleştirmesinde istatistiki olarak önemli çıkmıştır $(\mathrm{p}<0.01)$. İki yılın birleştirilmiş verileri incelendiğinde; en yüksek meyve boyu $69.0 \mathrm{~mm}$ ile herbisitle mücadele yapılan parsellerden elde edilirken, en düşük meyve boyu F. rubra rubra ekili parsellerden $(45.2 \mathrm{~mm})$ elde edilmiştir. Araştırmada, y1l bazında değerlendirildiğinde en küçük meyve boyu; 2013 yılında $V$. villosa (44.2 mm), 2014 yilında ise $F$. rubra rubra $(46.0 \mathrm{~mm})$ ekili parsellerde ölçülmüştür. Bununla birlikte en küçük meyve boyu açısından 2013 yılında $V$. villosa ve $F$. rubra rubra parselleri birbirine çok yakın değerlerden oluşmuş olup, aralarındaki farklılık istatistiksel olarak önemsiz bulunmuştur. En büyük meyve boyu değeri 2013 yılında herbisitle mücadele edilen parsellerde $(67.3 \mathrm{~mm})$ belirlenmiş; 2014 yılında ise en büyük boya sahip Trabzon hurması meyveleri $F$. arundinaceae $(73.0 \quad \mathrm{~mm})$ parsellerinden elde edilmesine rağmen, istatistiki olarak herbisitle mücadele edilen parseller ile (70.6 $\mathrm{mm}$ ) aynı grupta yer almıştır (Tablo 3).

\section{2. Örtücü bitkilerin Trabzon hurmasında meyve enine etkisi}

Yabanc1 otlarla mücadele uygulamalarının Trabzon hurmasında meyve enine etkisine ait veriler Tablo 4'te verilmiş olup, uygulamalar arasındaki farklılıklar yıllar bazında ve yıl birleștirilmesinde istatistiki olarak çok önemli $(\mathrm{p}<0.01)$ bulunmuştur. İki yıl birlikte değerlendirildiğinde, en yüksek meyve eni $F$.
Tablo 3. Örtücü bitkilerin Trabzon hurmasında meyve boyuna etkisi $(\mathrm{mm})^{*}$

\begin{tabular}{llll}
\hline Uygulamalar & 2013 & 2014 & Ortalama \\
\hline T. repens & $52.5 \mathrm{bc}$ & $56.0 \mathrm{c}$ & $54.2 \mathrm{~cd}$ \\
F. rubra rubra & $44.5 \mathrm{de}$ & $46.0 \mathrm{~d}$ & $45.2 \mathrm{e}$ \\
F. arundinaceae & $45.6 \mathrm{de}$ & $73.0 \mathrm{a}$ & $59.3 \mathrm{~b}$ \\
Tr+Frr+Fa karışımı & $47.3 \mathrm{ce}$ & $55.4 \mathrm{c}$ & $51.3 \mathrm{~d}$ \\
$V$. villosa & $44.2 \mathrm{e}$ & $58.2 \mathrm{c}$ & $51.2 \mathrm{~d}$ \\
T. meneghinianum & $50.5 \mathrm{~cd}$ & $57.2 \mathrm{c}$ & $53.8 \mathrm{~cd}$ \\
Herbisitle mücadele & $67.3 \mathrm{a}$ & $70.6 \mathrm{a}$ & $69.0 \mathrm{a}$ \\
Mekanik mücadele & $48.0 \mathrm{ce}$ & $65.2 \mathrm{~b}$ & $56.6 \mathrm{bc}$ \\
Yabanc1 otlu kontrol parseli & $58.2 \mathrm{~b}$ & $59.4 \mathrm{c}$ & $58.8 \mathrm{~b}$ \\
\hline
\end{tabular}

Tr: T. repens $(\% 40)$, Frr: F. rubra rubra $(\% 30)$, Fa: F. arundinacea (\% 30), *: Sütunlar bazında, aynı harfle gösterilen ortalamalar arasında farkl111k yoktur.

Tablo 4. Örtücü bitkilerin Trabzon hurmasında meyve enine etkisi $(\mathrm{mm})^{*}$

\begin{tabular}{lllc}
\hline Uygulamalar & 2013 & 2014 & Ortalama \\
\hline T. repens & $62.1 \mathrm{bc}$ & $65.3 \mathrm{~cd}$ & $63.7 \mathrm{~b}$ \\
F. rubra rubra & $72.6 \mathrm{a}$ & $70.3 \mathrm{bc}$ & $71.5 \mathrm{a}$ \\
F. arundinaceae & $71.2 \mathrm{a}$ & $78.2 \mathrm{a}$ & $74.7 \mathrm{a}$ \\
Tr+Frr+Fa karışımı & $61.7 \mathrm{c}$ & $63.4 \mathrm{~d}$ & $62.6 \mathrm{~b}$ \\
V. villosa & $49.6 \mathrm{~d}$ & $75.1 \mathrm{ab}$ & $62.3 \mathrm{~b}$ \\
T. meneghinianum & $51.9 \mathrm{~d}$ & $76.7 \mathrm{a}$ & $64.3 \mathrm{~b}$ \\
Herbisitle mücadele & $68.1 \mathrm{ab}$ & $74.6 \mathrm{ab}$ & $71.3 \mathrm{a}$ \\
Mekanik mücadele & $49.6 \mathrm{~d}$ & $70.2 \mathrm{bc}$ & $59.9 \mathrm{~b}$ \\
Yabanc1 otlu kontrol parseli & $59.9 \mathrm{ab}$ & $67.5 \mathrm{~cd}$ & $63.7 \mathrm{~b}$ \\
\hline
\end{tabular}

Tr: T. repens $(\% 40)$, Frr: F. rubra rubra $(\% 30), \mathrm{Fa}: F$. arundinacea $(\% 30)$, *: Sütunlar bazında, aynı harfle gösterilen ortalamalar arasında farklılık yoktur.

arundinaceae ekili parsellerden $(74.7 \mathrm{~mm})$ elde edilmiştir. Ancak meyve eni bakımından; $F$. arundinaceae parselleri ile $F$. rubra rubra ve herbisitle mücadele yapılmış kontrol parselleri arasındaki farklılık istatistiki olarak önemsiz olup aynı grupta yer almışlardır. En küçük meyve eni, $59.9 \mathrm{~mm}$ ile mekanik mücadele parsellerinden elde edilmiş; ancak, mekanik mücadele parselleri ile yabanc1 otlu kontrol parseli, T. meneghinianum, $T$. repens, karışım ve $V$. villosa parselleri arasındaki farklılık önemsiz olup istatistiki açıdan aynı grupta yer almışlardır. Yıllar bazında değerlendirildiğinde 
ise en yüksek meyve eni değeri 2013 y1lında $F$. rubra rubra parsellerinden $(72.6 \mathrm{~mm})$ elde edilmiş olmakla birlikte, $F$. arundinaceae parselleri (71.2 $\mathrm{mm}$ ) arasındaki farklılık önemsiz olup, aynı grupta yer almışlardır. Çalışmanın 2014 yılında ise en yüksek değerler $F$. arundinaceae $(78.2 \mathrm{~mm})$ ve $T$. meneghinianum $(76.7 \mathrm{~mm})$ parsellerinde ölçülmesine rağmen; örtücü bitki olarak kullanılan bu bitkilere ait parseller ile $V$. villosa $(75.1 \mathrm{~mm})$ ve herbisitle kontrol parsellerinden elde edilen meyve eni değerleri $(74.6 \mathrm{~mm})$ arasındaki farklılık istatistiki olarak önemsiz bulunmuştur. En düşük meyve eni değeri 2013 yılında, V. Villosa (49.6 $\mathrm{mm})$, mekanik mücadele $(49.6 \mathrm{~mm})$ ve $T$. meneghinianum (51.9 mm) parsellerinden; 2014 yılında ise, karışım parsellerinde $(63.4 \mathrm{~mm})$ tespit edilmiştir (Tablo 4).

\section{3. Örtücü bitkilerin Trabzon hurmasında meyve şekil indeksine etkisi}

Çalışmada uygulamaların Trabzon hurmasında meyve şekil indeksine etkisi istatistiki açıdan çok önemli $(\mathrm{p}<0.01)$ çıkmıştır. İki yıllık veriler birlikte değerlendirildiğinde; en yüksek meyve şekil indeksi değeri $T$. meneghinianum parselinden (1.15) elde edilirken, şekil indeksi açısından $T$. meneghinianum ve $V$. villosa parselleri (1.10) arasındaki farklılık istatistiki olarak önemsiz bulunmuştur. Çalışmada en düşük meyve şekil indeksi değeri ise $F$. arundinaceae parsellerinden (0.80) elde edilmiştir. Yıllar bazında değerlendirildiğinde ise 2014 yılında elde edilen değerler 2013 yılından daha yüksek çıkmıştır. En yüksek şekil indeksi değeri 2013 y1lında herbisitle kontrol parselinden (0.98), 2014 yilında ise $F$. rubra rubra parselinden (1.52) elde edilmiştir. En düşük şekil indeksi değeri 2013 yilında $F$. rubra rubra parselinden (0.63), 2014 yllinda ise herbisitle mücadele parsellerinden (1.07) elde edilmiştir (Tablo 5).

\section{4. Örtücü bitkilerin Trabzon hurmasında meyve ağırlığına etkisi}

Örtücü bitkilerin Trabzon hurmasında kalite unsurlarından meyve ağırlığına etkisi, yapılan varyans analiz sonuçlarına göre istatistiki olarak çok önemli $(\mathrm{p}<0.01)$ bulunmuştur. Buna göre iki y1l birlikte değerlendirildiğinde, en yüksek Trabzon hurması meyve ağırlığı $165.5 \mathrm{~g}$ ile $F$. arundinaceae ekili parsellerden elde edilmiştir. En düşük meyve ağırlığı ise $109.9 \mathrm{~g}$ ile çok yıllık örtücü bitkilerin karışım halinde ekildiği parsellerden elde edilmiştir. Yıllar bazında değerlendirildiğinde ise en yüksek meyve ağırlığ1 2013 yilında T. repens parsellerinden (120.3 g), 2014 yilinda ise $F$. arundinaceae parsellerinden (233.2 g) elde edilirken; en düşük meyve ağırlığı
2013 y1lında T. meneghinianum parsellerinden $(57.0 \mathrm{~g}), 2014$ yılında ise karışım parsellerinden (132.1 g) elde edilmiştir (Tablo 6).

Tablo 5. Örtücü bitkilerin Trabzon hurmasında meyve şekil indeksine etkisi*

\begin{tabular}{lccc}
\hline Uygulamalar & 2013 & 2014 & Ortalama \\
\hline T. repens & $0.80 \mathrm{~b}$ & $1.18 \mathrm{c}$ & $0.90 \mathrm{de}$ \\
F. rubra rubra & $0.63 \mathrm{c}$ & $1.52 \mathrm{a}$ & $1.08 \mathrm{bc}$ \\
F. arundinaceae & $0.66 \mathrm{c}$ & $1.10 \mathrm{c}$ & $0.80 \mathrm{f}$ \\
Tr+Frr+Fa karışımı & $0.78 \mathrm{~b}$ & $1.15 \mathrm{c}$ & $0.96 \mathrm{e}$ \\
V. villosa & $0.90 \mathrm{a}$ & $1.30 \mathrm{~b}$ & $1.10 \mathrm{ab}$ \\
T. meneghinianum & $0.97 \mathrm{a}$ & $1.30 \mathrm{~b}$ & $1.15 \mathrm{a}$ \\
Herbisitle mücadele & $0.98 \mathrm{a}$ & $1.07 \mathrm{c}$ & $1.02 \mathrm{ce}$ \\
Mekanik mücadele & $0.96 \mathrm{a}$ & $1.09 \mathrm{c}$ & $1.03 \mathrm{ce}$ \\
Yabanc1 otlu kontrol parseli & $0.96 \mathrm{a}$ & $1.13 \mathrm{c}$ & $1.05 \mathrm{bd}$ \\
\hline
\end{tabular}

Tr: T. repens (\% 40), Frr: F. rubra rubra (\% 30), Fa: F. arundinacea (\% 30), *: Sütunlar bazında, aynı harfle gösterilen ortalamalar arasında farklilık yoktur.

Tablo 6. Örtücü bitkilerin Trabzon hurmasında meyve ağırlığına etkisi $(\mathrm{g})^{*}$

\begin{tabular}{lccc}
\hline Uygulamalar & 2013 & 2014 & Ortalama \\
\hline T. repens & $120.3 \mathrm{a}$ & $144.8 \mathrm{df}$ & $132.6 \mathrm{~b}$ \\
F. rubra rubra & $108.9 \mathrm{ab}$ & $135.2 \mathrm{ef}$ & $122.1 \mathrm{bc}$ \\
F. arundinaceae & $97.7 \mathrm{bc}$ & $233.2 \mathrm{a}$ & $165.5 \mathrm{a}$ \\
Tr+Frr+Fa karışımı & $87.8 \mathrm{~cd}$ & $132.1 \mathrm{f}$ & $109.9 \mathrm{c}$ \\
V. villosa & $57.4 \mathrm{ef}$ & $221.9 \mathrm{ab}$ & $139.7 \mathrm{~b}$ \\
T. meneghinianum & $57.0 \mathrm{f}$ & $218.6 \mathrm{ac}$ & $137.8 \mathrm{~b}$ \\
Herbisitle mücadele & $75.1 \mathrm{de}$ & $177.7 \mathrm{ce}$ & $126.4 \mathrm{bc}$ \\
Mekanik mücadele & $74.7 \mathrm{df}$ & $190.2 \mathrm{bc}$ & $132.4 \mathrm{~b}$ \\
Yabanc1 otlu kontrol parseli & $74.7 \mathrm{df}$ & $185.3 \mathrm{bd}$ & $130.0 \mathrm{bc}$ \\
\hline Tr: T. repens $(\%$ 40), Frr: F. rubra rubra $\%$ 30), Fa: F. arundinacea \\
(\% 30), *: Sütunlar baznda, ayn harfle gösterilen ortalamalar arasinda \\
farkll1lk yoktur.
\end{tabular}

\section{5. Örtücü bitkilerin Trabzon hurmasında SÇKM oranına etkisi}

Trabzon hurması bahçelerinde, örtücü bitkilerin meyvelerin SÇKM miktarına etkilerinin belirlenmesi amacıyla elde edilen sonuçlar yıllar bazında ve yıl birleştirmesi olarak varyans analizine tabi tutulmuş; analiz sonuçlarına göre, uygulamalar arasındaki farklılıklar istatistiksel önemli $(\mathrm{p}<0.05) \quad$ çıkmıştır. İki yıl birlikte değerlendirildiğinde en yüksek SÇKM oranına sahip meyveler, çok yıllık örtücü bitkilerin karışım halinde ekildiği parsellerden (\% 21.2) elde edilmiş, ancak karışım parselleri ile $F$. arundinaceae ve $T$. meneghinianum parselleri arasındaki farklılık önemli bulunmamıştır. SÇKM açısından en düşük değer ise $V$. villosa ekili parsellerden (\% 18.3) elde edilmiştir. Yıllar bazında değerlendirildiğinde ise en yüksek SÇKM miktarı 2013 yılında $T$. meneghinianum parsellerinden (\% 22.8), 2014 yılında ise çok yıllık örtücü bitkilerin karışım halinde ekildiği parsellerden $\left(\begin{array}{ll}\% & 20.6\end{array}\right)$ elde edilirken; en düşük SÇKM miktarı ise 2013 yılında $V$. villosa (\% 19.4) ve T. repens (\% 20.1) ekili parsellerden, 2014 y1lında ise yabancı otlu kontrol parsellerinden (\% 15.9) elde edilmiştir (Tablo 7). 
Tablo 7. Örtücü bitkilerin Trabzon hurmasında SÇKM oranına etkisi (\%) ${ }^{*}$

\begin{tabular}{llll}
\hline Uygulamalar & 2013 & 2014 & Ortalama \\
\hline T. repens & $20.1 \mathrm{~d}$ & $17.9 \mathrm{be}$ & $19.0 \mathrm{~cd}$ \\
F. rubra rubra & $20.6 \mathrm{~cd}$ & $17.6 \mathrm{ce}$ & $19.1 \mathrm{~cd}$ \\
F. arundinaceae & $22.2 \mathrm{ab}$ & $19.9 \mathrm{ab}$ & $21.1 \mathrm{ab}$ \\
Tr+Frr+Fa karışımı & $21.7 \mathrm{ac}$ & $20.6 \mathrm{a}$ & $21.2 \mathrm{a}$ \\
$V$. villosa & $19.4 \mathrm{~d}$ & $17.1 \mathrm{ce}$ & $18.3 \mathrm{~d}$ \\
T. meneghinianum & $22.8 \mathrm{a}$ & $18.5 \mathrm{bd}$ & $20.7 \mathrm{ab}$ \\
Herbisitle mücadele & $21.8 \mathrm{ac}$ & $16.7 \mathrm{de}$ & $19.3 \mathrm{~cd}$ \\
Mekanik mücadele & $20.7 \mathrm{bd}$ & $19.0 \mathrm{ad}$ & $19.9 \mathrm{bc}$ \\
Yabanc1 otlu kontrol parseli & $22.0 \mathrm{ac}$ & $15.9 \mathrm{e}$ & $18.9 \mathrm{~cd}$ \\
\hline Tr: T. repens $(\%$ 40), Frr: F. rubra rubra $(\% 30)$, Fa: F. arundinacea \\
(\% 30), *: Sütunlar bazında, aynı harfle gösterilen ortalamalar arasında \\
farklılı yoktur.
\end{tabular}

\section{6. Örtücü bitkilerin Trabzon hurmasında verime etkisi}

Trabzon hurması bahçelerinde, uygulamalardan elde edilen verim $\left(\mathrm{kg} \mathrm{da}^{-1}\right)$ sonuçlarına varyans analizi uygulanmış olup, sonuçlar istatistiki olarak önemli bulunmuştur $(\mathrm{p}<0.05)$. İki yıllık veriler birlikte değerlendirildiğinde, en yüksek verim
$1617.5 \mathrm{~kg} \mathrm{da}^{-1}$ ile $V$. villosa parsellerinden elde edilmiştir. Ancak istatistiki olarak $V$. villosa parsellerinden elde edilen verim değerleri ile $T$. repens, F. arundinaceae, karışım, herbisitle kontrol ve mekanik mücadele yapılan parsellerden elde edilen verim değerleri arasında farklılık çıkmamıştır. Yapılan çalışma sonucunda en düşük verim ise $355.7 \mathrm{~kg} \mathrm{da}^{-1}$ ile yabanc1 otlu kontrol parsellerinden elde edilmiştir. Yıllar bazında yapılan değerlendirmede ise en yüksek verim değeri 2013 y1lında çok y1llık örtücü bitkilerin karışım halinde ekildiği parsellerden elde edilmiştir (1433.3 $\left.\mathrm{kg} \mathrm{da}{ }^{-1}\right)$. Bununla birlikte $T$. repens, $F$. arundinaceae, $V$. villosa ve $T$. meneghinianum ekili parseller arasında istatistiki olarak farklılık çıkmamış olup, aynı grupta yer almışlardır. Çalışmada, 2014 yılında ise en yüksek verim değerine $V$. villosa ekili parsellerde (1851.8

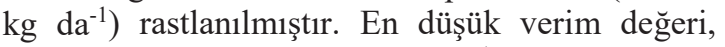
hem 2013 y1linda $\left(560.0 \mathrm{~kg} \mathrm{da}^{-1}\right)$ hem de 2014 y1lında $\left(151.4 \mathrm{~kg} \mathrm{da}^{-1}\right)$ yabanc1 otlu kontrol parsellerinde belirlenmiştir (Tablo 8).

Tablo 8. Örtücü bitkilerin Trabzon hurmasında verime etkisi $\left(\mathrm{kg} \mathrm{da}^{-1}\right)^{*}$

\begin{tabular}{|c|c|c|c|}
\hline Uygulamalar & 2013 & 2014 & Ortalama \\
\hline T. repens & $1416.6 \mathrm{a}$ & $658.3 \mathrm{ab}$ & $1037.5 \mathrm{ac}$ \\
\hline F. rubra rubra & $820.0 \mathrm{ab}$ & $339.8 \mathrm{~b}$ & $579.9 \mathrm{bc}$ \\
\hline F. arundinaceae & $1416.6 \mathrm{a}$ & $972.1 \mathrm{ab}$ & $1194.3 \mathrm{ab}$ \\
\hline Tr+Frr+Fa karışımı & $1433.3 \mathrm{a}$ & $379.3 \mathrm{ab}$ & $906.3 \mathrm{ac}$ \\
\hline V. villosa & $1383.3 \mathrm{a}$ & $1851.8 \mathrm{a}$ & $1617.5 \mathrm{a}$ \\
\hline T. meneghinianum & $1316.6 \mathrm{a}$ & $229.0 \mathrm{~b}$ & $772.8 \mathrm{bc}$ \\
\hline Herbisitle mücadele & $883.3 \mathrm{ab}$ & $891.0 \mathrm{ab}$ & $887.1 \mathrm{ac}$ \\
\hline Mekanik mücadele & $966.6 \mathrm{ab}$ & $755.2 \mathrm{ab}$ & $860.9 \mathrm{ac}$ \\
\hline Yabanc1 otlu kontrol parseli & $560.0 \mathrm{~b}$ & $151.4 \mathrm{~b}$ & $355.7 \mathrm{c}$ \\
\hline
\end{tabular}

Tr: T. repens (\% 40), Frr: F. rubra rubra $(\%$ 30), 88Fa: F. arundinacea $(\% 30)$, *: Sütunlar bazında, aynı harfle gösterilen ortalamalar arasında farklılık yoktur.

\section{Tartışma ve Sonuç}

Trabzon hurması bahçelerinde daha önce örtücü bitki çalışmasına rastlanılmamış olup, bu çalışma bu anlamda ilk çalışma niteliğindedir. Bu nedenle çalışmada elde edilen verilerin irdelenmesinde, diğer bitkilerde yapılan örtücü bitki çalışmalarına yer verilmiştir. Örtücü bitkiler, değişik bitkilerle gerek Türkiye'de gerekse dünyada yapılan çalışmalarda ele alınan bitkilerin kalite unsurlarına etkili olmuşlardır. Işık ve ark. (2018) elma bahçelerinde yaptıkları çalışmada, örtücü bitkilerin elmada kalite unsurlarını etkilediklerini tespit etmişler; yapılan bu çalışmada en yüksek meyve ağırlı̆̆ mücadele edilen parsellerden, meyve boyunun mekanik mücadele yapılan parsellerden elde edilmiş olmasına rağmen, örtücü bitkilerden $T$. repens, $F$. arundinacea ve $V$. villosa parsellerinin de iyi sonuçlar verdiği ifade edilmiştir. Elmada yapılan başka bir çalışmada; sürekli örtücü bitki kullanımının renklenmeyi arttırdığı, \% 75'ten fazla kırmızı renge sahip olan meyvelerin en yüksek yüzdesi sürekli çimlerle kaplı sisteminden elde edildiği belirtilmiştir (Kühn ve Pedersen, 2009). Muscas ve ark. (2017) tarafindan bağ alanlarında yapılan bir çalışmada buğdaygil örtücü bitkileri karışımının toprak işlemeye göre hasattaki şeker oranını arttırdığı bildirilmiştir. Çalışmada örtücü bitki uygulamaları toprak işlemeye göre antosiyanin ve polifenol konsantrasyonlarını da etkilemiştir. Bağda yapılan başka bir çalışmada ise örtücü bitkilerin üzümlerdeki toplam polifenol içeriğini ve şarap kalitesini arttırdığ edilmiştir (Xi ve ark., 2011).

$\mathrm{Bu}$ çalışmada en yüksek verim $V$. villosa parsellerinden elde edilmiştir. Örtücü bitki uygulamaları (Vicia spp) kontrol ile karşılaştırıldığında, Trabzon hurması bahçelerinde verimi artırmıştır (Tablo 8). Örtücü bitkilerin yabanc1 ot yoğunluğunu azaltması ve verimi etkilemesi konusunda elde edilen sonuçlar, daha önce örtücü bitkiler konusunda yürütülen farklı 
çalışmalardan elde edilen sonuçlarla paralellik arz etmektedir. Şöyle ki, Demir ve ark. (2019), Vicia spp. içeren farklı örtücü bitkilerin, örtücü bitkilerin bulunmadığı kontrol parselleri ile kıyaslandığında genellikle killi toprak yapısındaki kayısı bahçesindeki ortalama verim seviyelerini arttırdığını belirlemişlerdir. Verim miktarları esas olarak toprakların organik madde içeriğine bağlıdır (Demir ve ark., 2019; Demir ve Isik, 2019). Örtücü bitkilerinin kullanımında bile, iyi bir verim ve yeterli ağaç canlılığı sağlamak için organik gübreler gereklidir (Sánchez ve ark., 2007). Organik madde, toprakların fizikokimyasal ve biyolojik kalite özelliklerini doğrudan iyileştirir, buda verim seviyelerinin artmasina neden olur (Franzluebbers, 2002). Bununla birlikte, verimdeki artış miktarı yetiștirilen ürüne bağlı olarak değișir. Ayrıca, örtücü bitki türlerinin de verim artışları üzerinde etkileri vardır (Chalk, 1998). Işık ve ark. (2018) tarafından yapılan bir çalışmada örtücü bitki uygulamasının organik elma bahçelerinde ağaçların gelişimi ve elma verimi, örtücü bitki uygulaması yapılan parsellerde kontrole oranla daha yüksek bulunmuştur. $\mathrm{Bu}$ durumda örtücü bitki uygulamalarının verim unsurlarını arttırıcı etkisi olduğu ve bu bitkiler arasından ise $V$. villosa'nın diğer bitkilere oranla daha iyi sonuçlar verdiği anlaşılmıştır. Isik ve ark. (2013) tarafından gerçekleştirilen diğer bir çalışmada, örtücü bitkilerin kivi verimine etkisi değerlendirildiğinde yabancı otlu parsellerden en düşük verim elde edilirken, en yüksek verim $T$. meneghinianum parsellerinden elde edilmiştir.

Diğer kültür bitkilerinde olduğu gibi yabancı otlar Trabzon hurmasında da verim ve kalitede önemli kayılara sebebiyet vermektedir. $\mathrm{Bu}$ nedenle, Trabzon hurması bahçelerinde yabancı otlarla etkili bir şekilde mücadele edilmelidir. Trabzon hurması yetiştirilen alanlarda herbisitler yabancı otları kontrol etmek amaciyla yoğun şekilde kullanılmaktadır. Bununla birlikte herbisitlerin çevresel ve ticari olarak pek çok olumsuz etkisi bulunmasi nedeni ile herbisit kullanımını minimize edecek alternatif yabancı ot mücadele yöntemlerine başvurulması gerekmektedir. $\mathrm{Bu}$ çalışmanın sonuçlarına göre kültür bitkilerin verim kalitesini düşüren yabanc1 otlara karşı örtücü bitkilerin alternatif mücadele kaynağı olarak kullanılabileceği, aynı zamanda örtücü bitkiler diğer mücadele yöntemleri ile kıyaslandığında verim kaybı oluşturmadığı ortaya konulmuştur.

Yürütülmüş olan bu çalışma ile Trabzon hurması bahçelerindeki yabancı otların mücadelesinde yeni bir yöntem olan örtücü bitkilerin canlı malç olarak kullanılma olanakları araştırılmıştır. $\mathrm{Bu}$ çalışma sonucunda Trabzon hurması bahçelerinde sürdürülebilir üretim sistemleri için zemin yönetiminde örtücü bitkilerin kullanımının önemli olduğu görülmüştür. Trabzon hurması bahçelerinde sıra aralarında örtücü bitkilerin bulunması herbisitlere olan bağımlılı̆̆ ve herbisitlerden kaynaklı çevresel zararları da azaltacaktır. Bu amaçla yaz aylarının kurak geçtiği alanlarda Trabzon hurması sıra aralarında kışlık y1llık örtücü bitki olarak $V$. villosa kullanımı tavsiye edilebilir. Sonbaharda ekilecek $V$. villosa Mayıs sonu Haziran başı gibi toprağa karıştırıldığında, hem toprağa organik madde sağlayarak toprak yapısını iyileştirecek hem de meyve verim ve kalitesine olumlu etkide bulunacaktır. Sonbahar ve kış boyunca bahçede bulunan $V$. villosa yabancı otların çıkışına izin vermeyecektir. Toprağa karıştırıldıktan sonra ise çürüyen $V$. villosa artıkları allelopatik olarak bir ay kadar yabancı otların çıkışını engelleyecektir. Yağışın yüksek olduğu Doğu Karadeniz Bölgesi gibi sulama rekabeti ve maliyetinin olmadığ alanlarda ise $F$. arundinaceae ve $T$. repens gibi çok y1llı örtücü bitkiler veya bunların birlikte karışımlarının kullanılması uygun olacaktır. Örtücü bitkiler ekilirken ağaç köklerine zarar vermemek ve rekabete neden olmamak için ağaçlara 1 m'den fazla yaklaşmamaya özen gösterilmelidir.

Türkiye'de örtücü bitki kullanımı elma yetiştiriciliği yapılan bazı büyük ticari bahçelerde başlamış olup, zamanla yaygınlaşacağı düşünülmektedir. Trabzon hurması gibi bahçelerde kullanımını artırmak için eğitim çalışmalarına da ağırlık verilmesi, kamu özel sektör iş birliği ile demonstrasyon bahçelerinin kurulması faydalı olacaktır.

\section{Teșekkür}

Bu çalışma, TÜBİTAK (TOVAG 1110647 No’lu proje) tarafindan desteklenmiştir.

\section{Kaynaklar}

Acar, Z., Ayan, İ., 2009. Melez üçgül, kırmızı üçgül, yer altı üçgülü ve gelemen üçgülü. R. Avcıŏglu, R. Hatipoğlu ve Y. Karadağ (Eds.), Yembitkileri, Cilt II, Baklagil Yem Bitkileri, İzmir, s. 376-386.

Alvarez, R., Steinbacha, H. S., De Paepe, J. L., 2017. Cover crop effects on soils and subsequent crops in the Pampas: A meta-analysis. Soil \& Tillage Research, 170: 53-65.

Anonim, 2019. Bitkisel Üretim İstatistikleri. (www.tuik.gov.tr.), (Erişim tarihi 02.12.2019).

Anonim, 2020. Meteorolojik Veri Arşiv ve Yönetim Sistemi. Meteoroloji 10. Bölge Müdürlüğü, Samsun.

Chalk, P.M., 1998. Dynamics of biologically fixed $\mathrm{N}$ in legume-cereal rotations: a review. Australian Journal of Agricultural Research, 49(3): 303-316. 
Çakmakçı, S., Aydınoğlu, B., 2009. Tüylü fiğ (Vicia villosa Roth). R. Avcioğlu, R. Hatipoğlu ve Y. Karadağ (Eds.), Yembitkileri, Cilt II, Baklagil Yem Bitkileri, İzmir, s. 410-416.

Demir, Z., Isik, D., 2019. Effects of cover crop treatments on some soil quality parameters and yield in a kiwifruit orchard in Turkey. Fresenius Environmental Bulletin, 28(9): 6988-6997.

Demir, Z., Tursun, N., Işık, D., 2019. Effects of different cover crops on soil quality parameters and yield in an apricot orchard. International Journal of Agriculture and Biology, 21(2): 399-408.

Elçi, Ş., 2005. Baklagil ve Buğdaygil Yem Bitkileri. T.C. Tarım ve Köyişleri Bakanlığı, Ankara.

Franzluebbers, A.J., 2002. Water infiltration and soil structure related to organic matter and its stratification with depth. Soil \& Tillage Research, 66(2): 197-205.

Hoagland, L., Carpenter-Boggs, L., Granatstein, D., Mazzola, M., Smith, J., Peryea, F., Reganold, J.P., 2008. Orchard floor management effects on nitrogen fertility and soil biological activity in a newly established organic apple orchard. Biology and Fertility of Soils, 45: 11-18.

Isık, D., Kaya, E., Ngouajio, M., Mennan, H., 2009. Summer cover crops for weed management and yield improvement in organic lettuce (Lactuca sativa) production. Phytoparasitica, 37: 193-203.

Isik, D., Dok, M., Ak, K., Macit, I., Demir, Z., Mennan, H., 2013. Possible use of cover crops in weed control on kiwi orchards in Black Sea Region of Turkey. In: Proceedings of the Joint Workshop of The Ewrs Working Groups: Novel and Sustainable Weed Management in Arid and Semi-arid Agro Ecosystems and Weed Mapping, 29 September-3 October, Greece, pp.45.

Isik, D., Dok, M., Ak, K., Macit, I., Demir, Z., Mennan, H., 2014. Use of cover crops for weed suppression in hazelnut (Corylus avellana L.) in Turkey. Communications in Agricultural and Applied Biological Sciences,79(2): 105-110.

Işık, D., Türkmen, G., Demir, Z., Macit, İ., 2018. Yarı bodur elma bahçelerinde bazı örtücü bitkilerin verim ve kalite üzerine etkileri. Erciyes Üniversitesi Fen Bilimleri Enstitüsü Fen Bilimleri Dergisi, 3(2): 6074.
Kır, B., Avcıoğlu, R., Geren, H., 2009. Ak üçgül (Trifolium repens L.). R. Avcıŏlu, R. Hatipoğlu ve Y. Karadağ (Eds.), Yembitkileri, Cilt II, Baklagil Yem Bitkileri, İzmir, s. 359-362.

Kitiş, Y.E., 2010. Meyve bahçelerinde örtücü bitki kullanımı. Tarım Türk Dergisi, 22: 36-38.

Kühn, B.F., Pedersen, H.L., 2009. Cover crop and mulching effects on yield and fruit quality in unsprayed organic apple production. European Journal of Horticultural Sciences, 74(6): 247-256.

Mullinix, K., Granatstein, D., 2011. Potential nitrogen contributions from legumes in Pacific Northwest apple orchards. International Journal of Fruit Science, 11(1): 74-87.

Muscas, E., Cocco, A., Mercenaro, L., Cabras, M., Lentini, A., Porqueddu, C., Nieddu, G., 2017. Effects of vineyard floor cover crops on grapevine vigor, yield, and fruit quality, and the development of the vine mealybug under a Mediterranean climate. Agriculture, Ecosystems \& Environment, 237: 203-212.

Onur, C., Onur, S., 1997. Karadeniz Bölgesi Trabzon hurmas1 seleksiyonu. Derim Dergisi, 14(4): 146156.

Özcan, M., 2005. Trabzon Hurması Yetiştiriciliği. Hasat Yayınc1lı, İstanbul.

Robacer, M., Canali, S., Kristensen, H.L., Bavec, F., Mlakar, S.G., Jakop, M., Bavec, M., 2016. Cover crops in organic field vegetable production. Scientia Horticulturae, 208: 104-110.

Sánchez, E.E., Giayetto, A., Cichón, L., Fernández, D.M., Aruani, M.C., Curetti, M., 2007. Cover crops in Xuence soil properties and tree performance in an organic apple (Malus domestica Borkh) orchard in northern Patagonia. Plant Soil, 292: 193-203.

Tursun, N., Işık, D., Demir, Z., Jabran, K., 2018. Use of living, mowed, and soil-incorporated cover crops for weed control in apricot orchards. Agronomy, 8(8): 150.

Xi, Z.M., Tao, Y.S., Zhang, L., Li, H., 2011. Impact of cover crops in vineyard on the aroma compounds of Vitis vinifera L. cv Cabernet Sauvignon wine. Food Chemistry, 127(2): 516-522. 